Article

\title{
Development of Facile and Simple Processes for the Heterogeneous Pd-Catalyzed Ligand-Free Continuous-Flow Suzuki-Miyaura Coupling
}

\author{
Tsuyoshi Yamada ${ }^{\circledR}$, Jing Jiang, Naoya Ito, Kwihwan Park, Hayato Masuda, Chikara Furugen, \\ Moeka Ishida, Seiya Ōtori and Hironao Sajiki *(i) \\ Laboratory of Organic Chemistry, Gifu Pharmaceutical University, 1-25-4 Daigaku-nishi, Gifu 501-1196, Japan; \\ yamada@gifu-pu.ac.jp (T.Y.); jiang@gifu-pu.ac.jp (J.J.); fwd8821pjl@gmail.com (N.I.); \\ kwiffany.p@gmail.com (K.P.); hayato.m.gifu@gmail.com (H.M.); f.chikara0311@gmail.com (C.F.); \\ bud.blossoms15@gmail.com (M.I.); yaseinobigbird@gmail.com (S.Ō.) \\ * Correspondence: sajiki@gifu-pu.ac.jp; Tel.: +81-58-230-8100
}

Received: 10 September 2020; Accepted: 15 October 2020; Published: 19 October 2020

check for updates

\begin{abstract}
The Suzuki-Miyaura coupling reaction is one of the most widely utilized C-C bond forming methods to create (hetero)biaryl scaffolds. The continuous-flow reaction using heterogeneous catalyst-packed cartridges is a practical and efficient synthetic method to replace batch-type reactions. A continuous-flow ligand-free Suzuki-Miyaura coupling reaction of (hetero)aryl iodides, bromides, and chlorides with (hetero)aryl boronic acids was developed using cartridges packed with spherical resin (tertiary amine-based chelate resin: WA30)-supported palladium catalysts (7\% Pd/WA30). The void space in the cartridge caused by the spherical catalyst structures enables the smooth flow of a homogeneously dissolved reaction solution that consists of a mixture of organic and aqueous solvents and is delivered by the use of a single syringe pump. Clogging or serious backpressure was not observed.
\end{abstract}

Keywords: Suzuki-Miyaura coupling; palladium; continuous-flow reaction; ligand-free; chelate resin; aromatic chloride

\section{Introduction}

The Suzuki-Miyaura reaction [1-7] is robust and is one of the most reliable C-C bond-forming methods. It is utilized for the production of (hetero)biaryl structures, which are fundamental components of active pharmaceutical ingredients (APIs) [4,8-14], functional materials [15], and natural products $[16,17]$ in a variety of synthetic chemistry fields. The development of a highly active and durable heterogeneous Pd catalyst is important for minimizing toxic metal contamination in the products and reducing environmental pollution caused by metal leaching during the catalytic cycle in transition-metal-catalyzed coupling reactions and treatment after the reactions [18-22].

Continuous-flow reactions using a packed-bed cartridge filled with heterogeneous catalysts attracted considerable research interest as robust and reproducible reaction methods [23-28]. Because small amounts of substrate and reactants in the reaction solution were continuously introduced into the catalyst cartridge via a narrow tube and immediately contacted a large amount of catalyst, a higher reaction efficiency was achieved compared with the corresponding batch reactions using flasks and reaction vessels. Supported Pd catalysts packed in a cartridge can be safely utilized without deactivation or ignition because the catalyst is not exposed to air (especially atmospheric oxygen). Furthermore, the resulting reaction mixture is continuously collected at the outlet of the cartridge without the need of catalyst separation. 
The use of commercially abundant and inexpensive aryl boronic acids with inorganic bases is ideal to develop practical Suzuki-Miyaura coupling reactions under both batch and continuous-flow conditions [23-42]. Various heterogeneous Pd-catalyzed continuous-flow Suzuki-Miyaura reactions of aryl halides with aryl boronic acids in the presence of inorganic bases were established [29-42]. The organic and aqueous solvents were mixed in many cases with a pump to dissolve the substrate and reagent without clogging the flow reactors [29-33]. Because a complex optimization process to select reaction conditions such as solvent combination, flow rate, and substrate concentration is required, the use of a single reaction solution in which all reagents are homogeneously dissolved is advantageous. Some research groups developed continuous-flow Suzuki-Miyaura reactions using homogeneously dissolved solvents of $\mathrm{H}_{2} \mathrm{O}$ with highly polar organic solvents, such as alcohols [37,39-41], $\mathrm{N}, \mathrm{N}$-dimethylformamide (DMF) [34-36], MeCN [38], and tetrahydrofuran (THF) [40], to improve the solubility of aryl halides, aryl boronic acids, and inorganic bases. A continuous-flow ligand-free Suzuki-Miyaura reaction of aryl iodides and bromides with aryl boronic acid in an $\mathrm{EtOH} / \mathrm{H}_{2} \mathrm{O}$ mixed single solution using a 10\% Pd/C-packed catalyst cartridge was also developed [42]. However, high reaction temperatures and/or backpressures are often achieved using specific and expensive flow devices that are generally difficult to apply scale-up in productive use [34,35,39-42]. There is also a risk of clogging the cartridge and/or outlet of the flow tube by precipitation of reactants and/or products that are generated under harsh reaction conditions [37]. The use of highly dispersed heterogeneous powdered Pd catalysts diluted by silica or celite is an efficient technique to create void spaces and prevent pressure rise and clogging in the catalyst cartridge [29]. Based on these issues, the development of an efficient continuous-flow Suzuki-Miyaura reaction by introducing a homogeneously dissolved reaction solution into a spherical bead-supported Pd catalyst-packed cartridge with an appropriate void space is a suitable methodology to achieve an unrestricted and smooth flow.

Various spherical or monolithic polystyrene/divinylbenzene copolymer-supported (HP20 (Mitsubishi Chemical Corporation) [43], CM (Organo Corporation) [44], and AM (Organo Corporation) [44]) Pd catalysts (Pd/HP20 [20], Pd/CM [21], and Pd/AM [21]) were previously developed and successfully applied to ligand-free Suzuki-Miyaura, Mizoroki-Heck, and Sonogashira-type coupling reactions. Furthermore, a tertiary amine-functionalized polystyrene-divinylbenzene-based basic anion exchange (chelate) resin WA30 (Mitsubishi Chemical Corporation) [45-47]-supported Pd catalyst (7\% Pd/WA30) was also developed for the efficient and ligand-free Suzuki-Miyaura reactions of (hetero)aryl iodides, bromides, and chlorides under batch conditions $[48,49]$ and microwave-assisted Mizoroki-Heck reaction under continuous-flow conditions [50]. Herein, new practical, ligand-, and backpressure-free continuous-flow Suzuki-Miyaura reactions of (hetero)aryl iodides, bromides, and chlorides with (hetero)aryl boronic acids using a 7\% $\mathrm{Pd} / \mathrm{WA} 30$-packed catalyst cartridge were established. The spherical structure of $7 \% \mathrm{Pd} / \mathrm{WA} 30$ created an appropriate void space in the cartridge that enabled the smooth flow of the reaction solution. The present continuous-flow Suzuki-Miyaura coupling using 7\% Pd/WA30 proceeded efficiently by transferring a solution of aryl halides, aryl boronic acids, and bases by a syringe pump into the catalyst cartridge without any complex reaction system, equipment, and operations (Figure 1). 


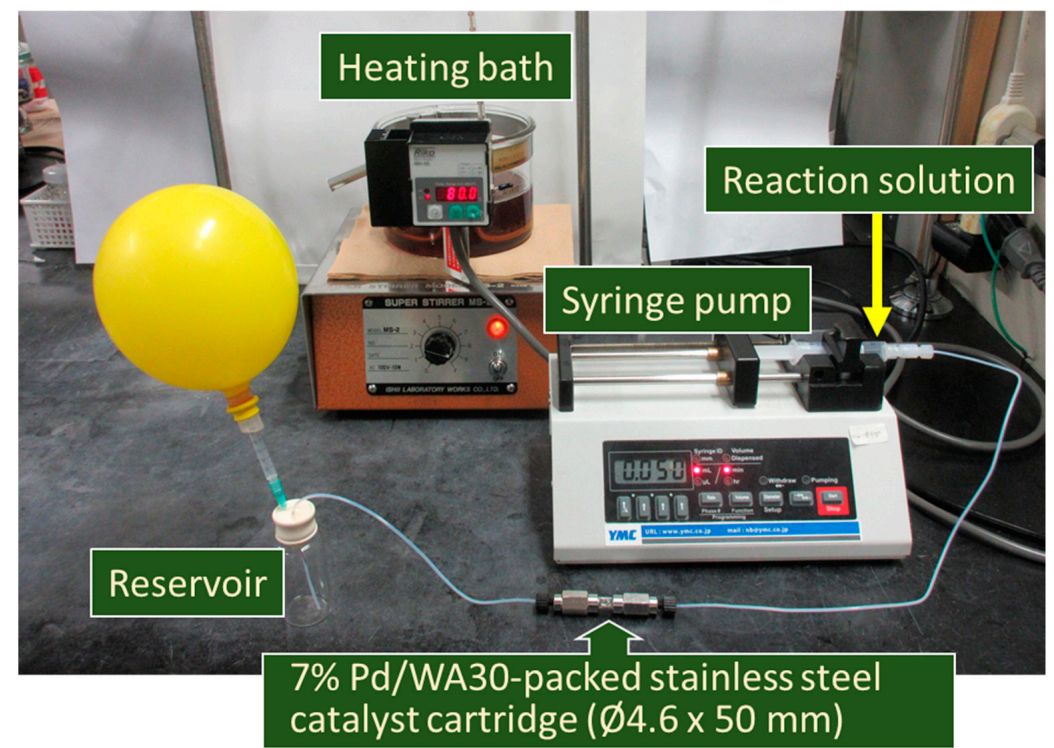

Figure 1. Continuous-flow apparatus for the Suzuki-Miyaura coupling reaction using a 7\% Pd/WA30packed catalyst cartridge.

\section{Results and Discussions}

\subsection{Continuous-Flow Suzuki-Miyaura Coupling of Aryl Iodides and Bromides with Aryl Boronic Acids}

The solubility of a mixture of 4 -iodoacetophenone $(\mathbf{1 a}, 0.5 \mathrm{mmol})$ and phenylboronic acid (3a, 1.2 eq., $0.6 \mathrm{mmol}$ ) with $\mathrm{K}_{3} \mathrm{PO}_{4}, \mathrm{NaOH}$, or $\mathrm{KOH}$ (2.0 eq., $1.0 \mathrm{mmol}$ ) in a mixed solvent of $\mathrm{H}_{2} \mathrm{O}$ and various organic solvents was initially investigated (see Supplementary Materials). As a result, it was observed that the combined use of $\mathrm{NaOH}$ or $\mathrm{KOH}$ with $\mathrm{H}_{2} \mathrm{O}(0.5 \mathrm{~mL})$ and 1,4-dioxane $(1.5 \mathrm{~mL})$ formed a homogeneously dissolved solution. In contrast, other combinations of bases with solvents resulted in an inhomogeneous mixture.

Next, continuous-flow Suzuki-Miyaura reaction efficiencies were investigated by transferring a solution of $1 \mathbf{a}(0.5 \mathrm{mmol})$, 3a (1.2 eq., $0.6 \mathrm{mmol})$, and $\mathrm{NaOH}$ or $\mathrm{KOH}\left(2.0\right.$ eq.) in $\mathrm{H}_{2} \mathrm{O} / 1$,4-dioxane $(0.5 \mathrm{~mL} / 1.5 \mathrm{~mL})$ into the $7 \% \mathrm{Pd} / \mathrm{WA} 30(100 \mathrm{mg})$-packed catalyst cartridge using a syringe pump at a flow rate of $0.05 \mathrm{~mL} / \mathrm{min}$ (Table 1). The coupling reaction proceeded smoothly at $25^{\circ} \mathrm{C}$ to obtain the corresponding 4-acetylbiphenyl (4aa), and the use of $\mathrm{KOH}$ indicated a slightly higher reaction efficiency ( $95 \%$ yield) compared with $\mathrm{NaOH}$ (77\% yield). However, both reactions were incomplete and a small amount of $1 \mathbf{a}$ (entry 1 vs. 2) remained unchanged. Compound 1a was completely coupled with 3a in the presence of $\mathrm{KOH}$ and increasing the amount of 7\% Pd/WA30 from $100 \mathrm{mg}$ to $200 \mathrm{mg}$ generated 4aa in quantitative yield, accompanied by turnover number (TON) and turnover frequency (TOF) of 3.8 and $0.1 \mathrm{~min}^{-1}$, respectively (entry 3). Furthermore, leached Pd species were never detected in the reaction mixture collected at the outlet of the cartridge using atomic absorption spectrophotometry (AAS, Pd detection limit: 1 ppm, see Supplementary Materials).

Using 4'-bromoacetophenone (2a) as a substrate, a higher reaction efficiency was achieved with $\mathrm{NaOH}$ compared with $\mathrm{KOH}$ to obtain 4 aa in $68 \%$ yield (entry 4 vs. 5). The increase in the catalyst cartridge temperature effectively activates the $\mathrm{C}-\mathrm{Br}$ bond $2 \mathbf{a}$ to produce $4 \mathrm{aa}$ in $74 \%$ yield at $60{ }^{\circ} \mathrm{C}$ (entry 6). Adding more $7 \% \mathrm{Pd} / \mathrm{WA} 30$ catalyst led to an increase in coupling selectivity and efficiency, resulting in a $95 \%$ yield with a TON and TOF of 3.6 and $0.1 \mathrm{~min}^{-1}$, respectively (entry 7).

Substrate applicability toward aryl iodides and bromides possessing a variety of functional groups at the 2-, 3-, or 4-positions of the benzene ring with aryl boronic acids was investigated under optimized reaction conditions (aryl iodides for Table 1, entry 3 and bromides for Table 1, entry 7). As the reactivity of 3'-iodoacetophenone (1b) and 2'-iodoacetophenone (1c) was significantly decreased, probably because of the steric hindrance of the acetyl group, the coupling of 3'-iodo- $(\mathbf{1 b})$ or 2'-iodoacetophenone (2b) with 
phenylboronic acid (3a) required 1.5 equivalents of $3 \mathbf{a}$ and heating to $80^{\circ} \mathrm{C}$ to obtain the corresponding 4aa in 99\% and 83\% isolated yield, respectively (Table 2, entries 1 and 3). The detailed reaction optimizations for coupling $\mathbf{1 b}$ and $\mathbf{1 c}$ are shown in the Supplementary Materials. The subsequent Suzuki-Miyaura coupling reactions of iodo- (1) and bromoarenes (2) and 1.5 equivalents of aryl boronic acids were conducted using a catalyst cartridge packed with $200 \mathrm{mg}$ of $7 \% \mathrm{Pd} / \mathrm{WA} 30$ based on the experimental results provided in the Supplementary Materials. Phenylation of iodoarenes bearing $\mathrm{EtO}_{2} \mathrm{C}(\mathbf{1 d}), \mathrm{Me}(\mathbf{1 e})$, or $\mathrm{MeO}(\mathbf{1 f})$ at the para position of the benzene ring of 3a smoothly occurred to afford the corresponding biaryls (4da, 4 ea, and 4 fa) in high yields $(89,84$, and $88 \%$, respectively), regardless of the electronic density of the benzene ring (entries 3-5). Iodobenzene (1g) efficiently reacted with 4-MeO- (3b) and 4-acetyl-phenylboronic acids (1f) to generate the corresponding $4 \mathbf{f a}$ and 4 aa in $72 \%$ and $96 \%$ yields, respectively (entries 6 and 7). Various bromobenzene derivatives bearing 3-Ac (2b), 2-Ac (2c), 4- $\mathrm{EtO}_{2} \mathrm{C} \mathrm{(2d),} \mathrm{4-Me} \mathrm{(2e),} \mathrm{and} \mathrm{4-MeO} \mathrm{(2f)} \mathrm{on} \mathrm{the} \mathrm{aromatic} \mathrm{ring} \mathrm{were} \mathrm{also}$ coupled with $3 \mathbf{a}$ to produce the desired biaryls (4ba, 4ca, $4 \mathbf{d a}$, 4ea, and $4 \mathbf{f a}$ ) in $43-81 \%$ isolated yields (entries 8-12). The arylation of unsubstituted bromobenzene $2 \mathbf{g}$ with $\mathbf{3 b}$, bearing an electron-donating methoxy group at the para position of the aromatic ring, was smoothly carried out to obtain the corresponding $4 \mathrm{fa}$ in $75 \%$ yield (entry 13 ).

Table 1. Optimization of the 7\% Pd/WA30-catalyzed continuous-flow Suzuki-Miyaura coupling reaction of $4^{\prime}$-iodo and $4^{\prime}$-bromo acetophenone (1a and $\mathbf{2 a}$ ) with phenylboronic acid (3a).

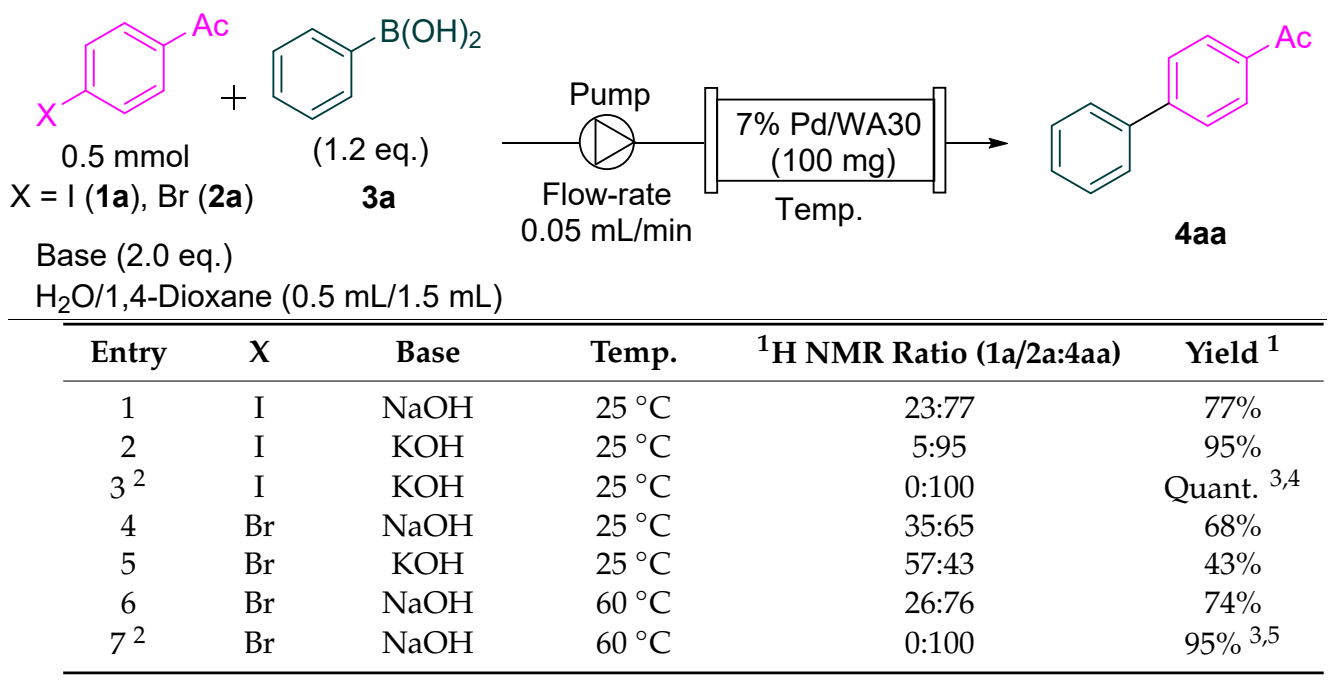

${ }^{1}$ Yield was determined by ${ }^{1} \mathrm{H}$ NMR using 1,1,2,2-tetrachloroethane as an internal standard. ${ }^{2}$ An amount of $200 \mathrm{mg}$ $7 \% \mathrm{Pd} / \mathrm{WA} 30$ was used. ${ }^{3}$ Isolated yield. ${ }^{4}$ turnover number (TON) and turnover frequency (TOF) for the coupling of $1 \mathbf{a}$ with $3 \mathbf{a}$ were 3.8 and $0.1\left(\mathrm{~min}^{-1}\right)$, respectively. ${ }^{5} \mathrm{TON}$ and TOF for the coupling of $\mathbf{2 a}$ with $3 \mathbf{a}$ were 3.6 and $0.1 \mathrm{~min}^{-1}$, respectively.

Next, the continuous-flow Suzuki-Miyaura reaction using the 7\% Pd/WA30-packed catalyst cartridge was applied to heteroaryl iodides and bromides with (hetero)aryl boronic acids (Figure 2). The coupling of 4-iodo pyridine (1h) with 3a efficiently generated the corresponding 4-phenylpyridine (4ha) in quantitative yield. However, the coupling of 3- and 2-iodopyridine (1i and $\mathbf{1 j}$ ) and 4-, 3-, and 2-bromopyridine ( $\mathbf{2} \mathbf{h}, \mathbf{2} \mathbf{i}$, and $\mathbf{2} \mathbf{j}$ ) was not successful. Corresponding phenylpyridines (4ha, $4 \mathbf{i a}$, and $4 \mathbf{j a}$ ) were obtained in relatively low yields (39\%-55\%) because of the poorer reactivity, probably based on the electronically biased character of the pyridine nuclei. The use of 2-iodothiophene (2k) as substrate led to the corresponding $4 \mathbf{k a}$ in $83 \%$ yield. Meanwhile, 5-formyl-2-phenyl-thiophene (4la) and 5-formyl-2-phenyl-furan (4ma) were obtained from 11 and $1 \mathrm{~m}$, respectively, under the same flow reaction conditions in moderate yields (both 53\%). The heteroaryl-heteroaryl coupling of $1 \mathbf{i}$ with 2-benzofuranboronic acid (3d) and 4-dibenzofuranboronic acid (3e) effectively provided heterobiaryls (4id and $4 \mathbf{i e}$ ) in $85 \%$ and quantitative yield, respectively. 
Table 2. Scope of substrate for the 7\% Pd/WA30-catalyzed continuous-flow Suzuki-Miyaura coupling reaction of $4^{\prime}$-iodo and $4^{\prime}$-bromobenzene derivatives (1 or $\left.\mathbf{2}\right)$ with aryl boronic acid (3). ${ }^{\text {a. }}$<smiles>[R]c1cccc([R])c1[Hg]O[Na]</smiles>

Base: $\mathrm{X}=\mathrm{I}(\mathbf{1}): \mathrm{KOH}(2.0$ eq. $)$ $X=\mathrm{Br}(2): \mathrm{NaOH}(2.0$ eq. $\mathrm{H}_{2} \mathrm{O} / 1,4$-Dioxane $=(0.5 \mathrm{~mL} / 1.5 \mathrm{~mL})$

\begin{tabular}{|c|c|c|c|c|c|}
\hline Entry & $X$ & $\mathbf{R}^{1}$ & $\mathbf{R}^{2}$ & Product & Yield $^{1}$ \\
\hline $1^{2}$ & \multirow{7}{*}{ I } & 3-Ac (1b) & $\mathrm{H}(\mathbf{3 a})$ & $4 \mathrm{ba}$ & Quant. (99) \\
\hline $2^{2}$ & & $2-A c(1 c)$ & $\mathrm{H}(\mathbf{3 a})$ & $4 \mathrm{ca}$ & $83 \%(83)$ \\
\hline 3 & & $4-\mathrm{EtO}_{2} \mathrm{C}(\mathbf{1 d})$ & $\mathrm{H}(3 \mathbf{a})$ & $4 d a$ & $89 \%(89)$ \\
\hline 4 & & 4-Me (1e) & $\mathrm{H}(3 \mathbf{a})$ & 4ea & $85 \%(84)$ \\
\hline 5 & & $4-\mathrm{MeO}(\mathbf{1 f})$ & $\mathrm{H}(\mathbf{3 a})$ & $4 \mathrm{fa}$ & $88 \%(88)$ \\
\hline 6 & & $\mathrm{H}(\mathbf{1 g})$ & $4-\mathrm{MeO}(3 \mathrm{~b})$ & $4 \mathrm{fa}$ & $72 \%(72)$ \\
\hline $7^{3}$ & & $\mathrm{H}(\mathbf{1 g})$ & $4-A c(3 c)$ & 4aa & Quant. (96) \\
\hline 8 & \multirow{6}{*}{$\mathrm{Br}$} & $3-A c(2 b)$ & $\mathrm{H}(\mathbf{3 a})$ & $4 \mathrm{ba}$ & $84 \%(81)$ \\
\hline 9 & & $2-A c(2 c)$ & $\mathrm{H}(3 \mathbf{a})$ & $4 \mathrm{ca}$ & $57 \%(57)$ \\
\hline 10 & & $4-\mathrm{EtO}_{2} \mathrm{C}(\mathbf{2 d})$ & $\mathrm{H}(3 \mathbf{a})$ & 4da & $50 \%(50)$ \\
\hline 11 & & 4-Me (2e) & $\mathrm{H}(3 \mathbf{a})$ & 4ea & $70 \%(80)$ \\
\hline 12 & & $4-\mathrm{MeO}(\mathbf{2 f})$ & $\mathrm{H}(\mathbf{3 a})$ & $4 \mathrm{fa}$ & $48 \%(43)$ \\
\hline $13^{4}$ & & $\mathrm{H}(2 \mathrm{~g})$ & $4-\mathrm{MeO}(3 \mathbf{b})$ & $4 \mathrm{fa}$ & $88 \%(75)$ \\
\hline
\end{tabular}

${ }^{1}$ Yield was determined by ${ }^{1} \mathrm{H}$ NMR using 1,1,2,2-tetrachloroethane as an internal standard. Isolated yield is shown in parentheses. ${ }^{2} 1.5$ equivalents of 3 a were used at $80{ }^{\circ} \mathrm{C}^{3}{ }^{3} \mathrm{H}_{2} \mathrm{O} / 1,4$-dioxane $(1.0 \mathrm{~mL} / 3.0 \mathrm{~mL})$ was used. ${ }^{4} \mathrm{H}_{2} \mathrm{O} / 1$,4-dioxane $(0.8 \mathrm{~mL} / 1.5 \mathrm{~mL})$ was applied.
$\mathrm{X}=\mathrm{Br}: 60^{\circ} \mathrm{C}$

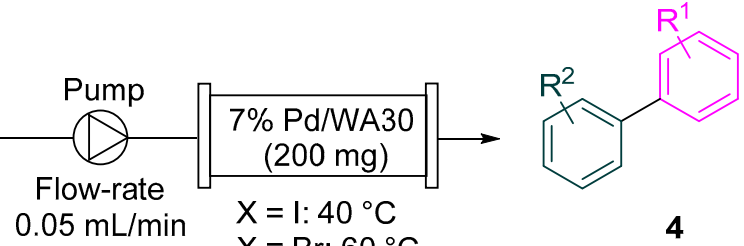




\subsection{Continuous-Flow Suzuki-Miyaura Coupling of Aryl Chlorides with Aryl Boronic Acids}

Next, the ligand- and backpressure-free continuous-flow Suzuki-Miyaura coupling reaction was conducted to link aryl chlorides with aryl boronic acids. A solution of 4'-chloroacetophenone (5a, $0.5 \mathrm{mmol})$; 3a (1.5 eq., $0.75 \mathrm{mmol})$; and $\mathrm{NaOH}, \mathrm{KOH}$, or $\mathrm{NaOtBu}(2.0$ eq., $1.0 \mathrm{mmol}$ ) in $\mathrm{H}_{2} \mathrm{O} / 1$,4-dioxane $(0.5 \mathrm{~mL} / 1.5 \mathrm{~mL})$ was transferred using a syringe pump at $0.05 \mathrm{~mL} / \mathrm{min}$ flow rate into the 7\% Pd/WA30 (100 mg)-packed catalyst cartridge, which was pre-heated at $80{ }^{\circ} \mathrm{C}$ in an oil bath (Table 3, entries 1-3). The use of $\mathrm{NaOH}$ resulted in a higher yield (23\%) of 4aa compared with that using $\mathrm{KOH}$ (19\% yield) and $\mathrm{NaO}$ Bu (17\% yield). An increase of $7 \% \mathrm{Pd} / \mathrm{WA} 30$ from $100 \mathrm{mg}$ to $500 \mathrm{mg}$ increased the conversion of 1a. However, the yield of the targeted 4aa was moderate at $45 \%$ (entry 4). Furthermore, a decrease in the flow rate from $0.05 \mathrm{~mL} / \mathrm{min}$ to $0.02 \mathrm{~mL} / \mathrm{min}$ was ineffective and generated the corresponding 4 aa in $30 \%$ yield (entry 5 ).

Table 3. Optimization of 7\% Pd/WA30-catalyzed continuous-flow Suzuki-Miyaura coupling reaction of 4 '-chloroacetophenone (5a) with phenylboronic acid (2a).

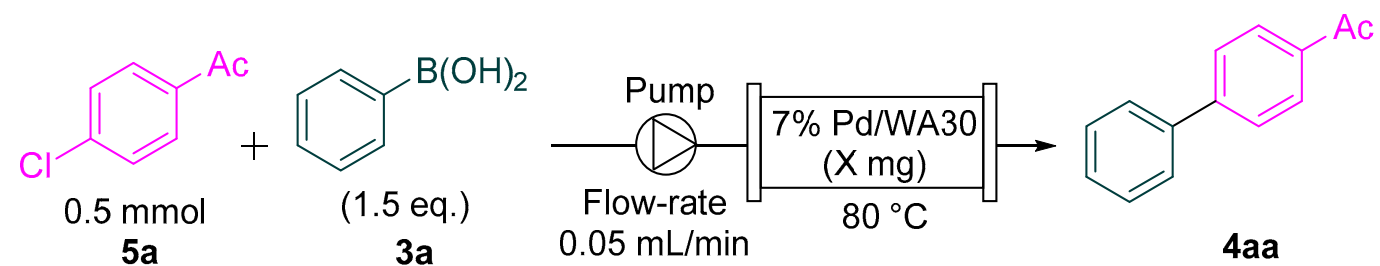

Base (2.0 eq.)

Solvent

\begin{tabular}{cccccc}
\hline Entry. & Base & $\mathbf{Y}(\mathbf{m g})$ & Solvent & $\mathbf{1}_{\mathbf{1}} \mathbf{H}$ NR Ratio (5a:4aa) & Yield $^{\mathbf{1}}$ \\
\hline 1 & $\mathrm{NaOH}$ & 100 & $\begin{array}{c}\mathrm{H}_{2} \mathrm{O} / 1,4 \text {-dioxane } \\
(0.5 / 1.5 \mathrm{~mL})\end{array}$ & $74: 26$ & $23 \%$ \\
2 & $\mathrm{KOH}$ & 100 & $\begin{array}{c}\mathrm{H}_{2} \mathrm{O} / 1,4 \text {-dioxane } \\
(0.5 / 1.5 \mathrm{~mL})\end{array}$ & $81: 19$ & $19 \%$ \\
3 & $\mathrm{Na}$ OBu & 100 & $\begin{array}{c}\mathrm{H}_{2} \mathrm{O} / 1,4 \text {-dioxane } \\
(0.5 / 1.5 \mathrm{~mL})\end{array}$ & $82: 18$ & $17 \%$ \\
4 & $\mathrm{NaOH}$ & 500 & $\begin{array}{c}\mathrm{H}_{2} \mathrm{O} / 1,4 \text {-dioxane } \\
(0.5 / 1.5 \mathrm{~mL})\end{array}$ & $13: 87$ & $45 \%$ \\
$5^{2}$ & $\mathrm{NaOH}$ & 500 & $\begin{array}{c}\mathrm{H}_{2} \mathrm{O} / 1,4-\text { dioxane } \\
(0.5 / 1.5 \mathrm{~mL})\end{array}$ & $57: 43$ & $30 \%$ \\
$6^{3}$ & $\mathrm{TBAF}$ & 100 & $\mathrm{THF}(2.0 \mathrm{~mL})$ & $0: 100$ & $68 \%$ \\
$7^{3}$ & $\mathrm{TBAF}$ & 300 & $\mathrm{THF}(2.0 \mathrm{~mL})$ & $0: 100$ & $68 \%$ \\
\hline
\end{tabular}

${ }^{1}$ Isolated yield. ${ }^{2}$ Flow rate of $0.02 \mathrm{~mL} / \mathrm{min} .{ }^{3} 0.25 \mathrm{mmol}$ of $5 \mathbf{a}$ and 2.0 equivalents of $2 \mathbf{a}$ were used.

The combination of base and solvent was crucial for developing the continuous-flow Suzuki-Miyaura coupling reaction using 7\% Pd/WA30-packed catalyst cartridges, not only to form a homogeneously dissolved reaction solution, but also to achieve a high reaction efficiency. Tetrabutylammonium fluoride (TBAF), which can act as a phase transfer catalyst and/or base, is used for the Pd-catalyzed Suzuki-Miyaura coupling reaction of aryl halides with aryl boronic acids and its esters to activate the Pd catalyst under batch conditions [51-54]. Based on these references, a variety of advantages of TBAF as a base, solubilizing agent, and activator of the $7 \% \mathrm{Pd} / \mathrm{WA} 30$ catalyst were utilized under continuous-flow conditions. After optimizing the reaction solvent (see the Supplementary Materials), it was observed that the addition of 2 equivalents of TBAF efficiently promoted the dissolution of $5 \mathbf{a}(0.25 \mathrm{mmol})$ and $3 \mathbf{a}(2.0$ eq., $0.50 \mathrm{mmol})$ in THF $(2 \mathrm{~mL})$. Furthermore, the reaction efficiency was considerably increased to achieve a $68 \%$ isolated yield by merely transferring a THF solution of $\mathbf{5 a}, \mathbf{3 a}$, and TBAF over the $7 \%$ Pd/WA30 (100 mg)-packed catalyst cartridge (entry 6). Because the increase of $7 \% \mathrm{Pd} / \mathrm{WA} 30$ from $100 \mathrm{mg}$ to $300 \mathrm{mg}$ did not improve the reaction efficiency (entry 6 vs. 7), the combined use of TBAF with THF and $100 \mathrm{mg}$ of 7\% Pd/WA30 was adopted as 
optimized conditions and used in the substrate applicability study. In the crude mixture of the reaction indicated in entry 6, leached Pd species were never detected with atomic absorption spectrophotometry (AAS, Pd detection limit: 1 ppm, see the Supplementary Materials).

While 3 '-chloroacetophenone ( $\mathbf{5 b}$ ) was coupled with $3 \mathbf{a}$ to obtain $4 \mathbf{b a}$ in $68 \%$ yield, the phenylation of $2^{\prime}$-chloroacetophenone (5c) with $3 \mathbf{a}$ afforded $4 \mathbf{c a}$ in only $13 \%$ yield because of the steric hindrance of the acetyl group (Figure 3). The coupling of ethyl 4-chlorobenzoate (5d) with 3a resulted in a $74 \%$ isolated yield of 4da. Chlorobenzenes bearing 4- $\mathrm{EtO}_{2} \mathrm{C}(5 \mathbf{e})$ and 4-Me (5f) groups reacted with 4-methoxy phenylboronic acid (3b), regardless of the electronic properties of the benzene ring, to generate the corresponding biaryls ( $4 \mathrm{db}$ and $4 \mathrm{eb}$ ) in $42 \%$ and $57 \%$ yields, respectively. The continuous-flow Suzuki-Miyaura reaction was also applied to the coupling of heteroaryl chlorides. 4-Chloropyridine hydrochloride ( $5 \mathrm{~g}$ ) was phenylated, increasing the amount of TBAF (3.0 eq.) to obtain 4 ha in $57 \%$ yield. An isolated yield of $80 \%$ of 4 ae was obtained when using a reactive heteroaryl boronic acid (3e) as a coupling partner of $\mathbf{5 a}$ with a TON and TOF of 3.0 and $0.8 \mathrm{~min}^{-1}$, respectively. Based on these results, the present continuous-flow Suzuki-Miyaura reaction using the 7\% Pd/WA30-packed catalyst cartridge was applied to the coupling of various (hetero)aryl chlorides with (hetero)aryl boronic acids in the presence of TBAF instead of $\mathrm{NaOH}$ as an additive. However, the reaction efficiency was affected by the electronic properties of the aromatics and the steric hindrance.
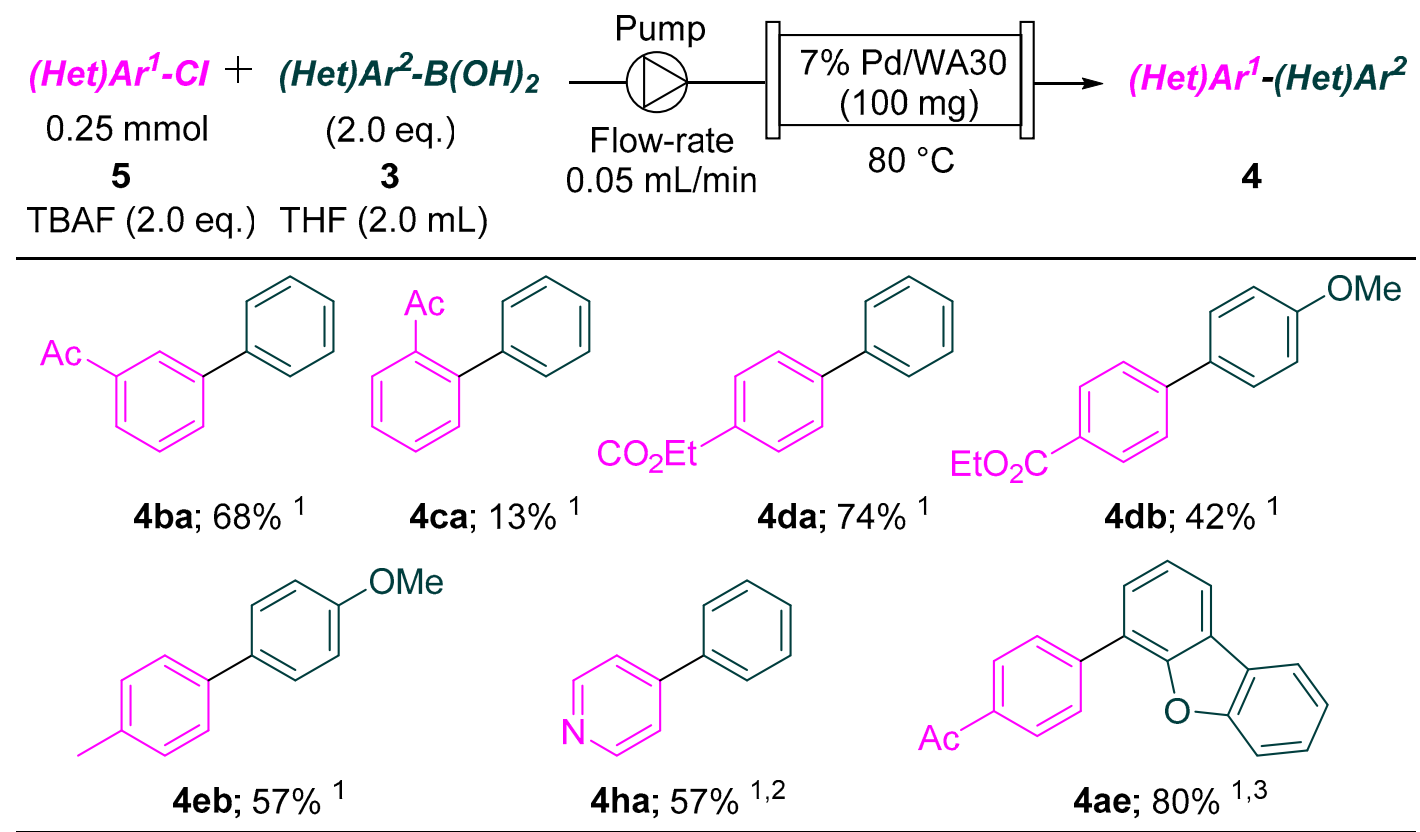

\footnotetext{
1 Isolated yield. ${ }^{2} 3.0$ equivalents of tetrabutylammonium fluoride (TBAF) and $1.75 \mathrm{~mL}$ of tetrahydrofuran (THF) were used. ${ }^{3} \mathrm{TON}$ and TOF for the coupling of $5 \mathbf{a}$ with $3 \mathbf{e}$ were 3.0 and 0.8 $\min ^{-1}$, respectively.
}

Figure 3. Scope of substrates of the 7\% Pd/WA30-catalyzed continuous-flow Suzuki-Miyaura coupling reaction of (hetero)aryl chlorides with (hetero)aryl boronic acids.

\subsection{Application of the Continuous-Flow Suzuki-Miyaura Coupling to Gram-Scale Synthesis}

A prolonged backpressure- and ligand-free continuous-flow Suzuki-Miyaura reaction was developed using a 7\% Pd/WA30-packed catalyst cartridge. 4'-Iodoacetophenone (1a, $10.0 \mathrm{mmol}$ ), phenylboronic acid $(2 \mathbf{a}, 15.0 \mathrm{mmol})$, and $\mathrm{KOH}(20.0 \mathrm{mmol})$ were dissolved in a mixed solvent of $\mathrm{H}_{2} \mathrm{O}(10 \mathrm{~mL})$ and 1,4-dioxane $(30 \mathrm{~mL})$. The homogeneously dissolved reaction solution was pumped through the cartridge packed with $200 \mathrm{mg}$ of $7 \% \mathrm{Pd} / \mathrm{WA} 30$ at a flow rate of $0.05 \mathrm{~mL} / \mathrm{min}$ (Scheme 1). The coupling efficiently and continuously proceeded for $14 \mathrm{~h}$ to obtain the corresponding $4 \mathrm{aa}$ in quantitative yield $(2.0 \mathrm{~g})$ with a TON and TOF of 76.1 and $5.4 \mathrm{~h}^{-1}$ and without catalyst deactivation 
during the entire reaction period. Therefore, the continuous-flow Suzuki-Miyaura coupling reaction can be easily applied for prolonged gram-scale biaryl syntheses.

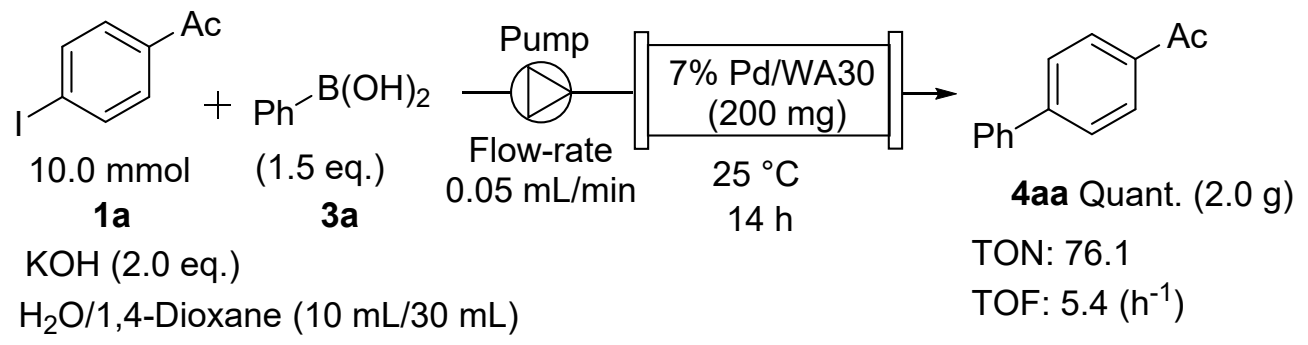

Scheme 1. Procedure for the Continuous-Flow Suzuki-Miyaura Coupling Reaction over an Extended Time.

\section{Materials and Methods}

\subsection{General Information}

All reagents and solvents were obtained from commercial sources (Tokyo Chemical Industry Co., Ltd, Chuo, Tokyo, Japan; FUJIFILM Wako Pure Chemical Industries, Ltd., Osaka, Japan; Sigma-Aldrich Japan Co., Meguro, Tokyo, Japan) and used without further purification. The dimethylamine-immobilized polymer WA30 was obtained from Mitsubishi Chemical Corporation (Chiyoda, Tokyo, Japan). $\mathrm{Pd}(\mathrm{OAc})_{2}$ was obtained from N.E. Chemcat Corporation (Minato, Tokyo, Japan). Flash column chromatography was performed using Silica Gel $60 \mathrm{~N}$ (Kanto Chemical Co. Inc., Chuo, Tokyo, Japan, 63-210 $\mu \mathrm{m}$ spherical, neutral). The ${ }^{1} \mathrm{H}$ and ${ }^{13} \mathrm{C}$ NMR spectra were recorded on a JEOL ECA-500 (500 MHz for ${ }^{1} \mathrm{H}$ NMR and $125 \mathrm{MHz}$ for ${ }^{13} \mathrm{C}$ NMR) and ECZ-400 (400 MHz for ${ }^{1} \mathrm{H}$ NMR and $100 \mathrm{MHz}$ for ${ }^{13} \mathrm{C}$ NMR) spectrometers. $\mathrm{CDCl}_{3}$ was used as solvent for the NMR measurements (LEOL Ltd., Akishima, Tokyo, Japan). The chemical shifts (d) are expressed in parts per million and internally referenced ( $0.00 \mathrm{ppm}$ for tetramethylsilane). All ${ }^{1} \mathrm{H}$ NMR spectra of known products were identical to those reported in the literature.

\subsection{Preparation of $7 \%$ Pd/WA30}

A suspension of dry WA30 (3.00 g, colorless particles) in an ethyl acetate solution (30 mL) of $\mathrm{Pd}(\mathrm{OAc})_{2}$ (2.12 mmol (226 mg; palladium)) was stirred under argon atmosphere at $25{ }^{\circ} \mathrm{C}$ for $4 \mathrm{~d}$. The resulting yellow solid was collected by filtration ( $1 \mathrm{~mm}$ filter paper), washed with $\mathrm{H}_{2} \mathrm{O}(10 \mathrm{~mL} \times 3)$, ethyl acetate $(10 \mathrm{~mL} \times 3)$, and $\mathrm{MeOH}(10 \mathrm{~mL} \times 3)$, and dried in vacuo for $24 \mathrm{~h}$. The filtrate was transferred to a $100 \mathrm{~mL}$ volumetric flask and diluted to $100 \mathrm{~mL}$ with $\mathrm{MeOH}$. Leached Pd species were not detected (detection limit: $<1 \mathrm{ppm}$ ) in the diluted filtrate using atomic absorption spectrometry (SHIMADZU AA-7000). The collected solid was then stirred with hydrazine monohydrate $\left(\mathrm{NH}_{2} \mathrm{NH}_{2} \cdot \mathrm{H}_{2} \mathrm{O}\right)(310.0 \mu \mathrm{L}$, $6.37 \mu \mathrm{mol})$ in $\mathrm{H}_{2} \mathrm{O}(30 \mathrm{~mL})$ for $24 \mathrm{~h}$ at $25^{\circ} \mathrm{C}$ under argon atmosphere. A pale gray solid was collected by filtration (1 mm filter paper), washed with $\mathrm{H}_{2} \mathrm{O}(10 \mathrm{~mL} \times 3)$ and $\mathrm{MeOH}(10 \mathrm{~mL} \times 3)$, and dried in vacuo for $24 \mathrm{~h}$ to generate Pd/WA30 (3.23 g). The filtrate was transferred to a $100 \mathrm{~mL}$ volumetric flask and diluted to $100 \mathrm{~mL}$ with $\mathrm{MeOH}$. Palladium species were not observed in the diluted filtrate (detection limit: $<1$ ppm). Palladium species absorbed on WA30 were not detected. Thus, the palladium content of Pd/WA30 (ethyl acetate) was estimated to be approximately $7 \%$ [(2260)/3230 $\times 100]$.

\subsection{Experimental Procedures}

3.3.1. Procedure for the Continuous-Flow Suzuki-Miyaura Coupling of Aryl Iodides and Bromides with Aryl Boronic Acids

A solution of aryl iodide or bromide (1 or 2, $0.50 \mathrm{mmol})$, aryl boronic acid $(3,0.75 \mathrm{mmol})$, and $\mathrm{NaOH}$ or $\mathrm{KOH}(1.0 \mathrm{mmol})$ in a mixed solvent of $\mathrm{H}_{2} \mathrm{O}(0.5 \mathrm{~mL})$ and 1,4-dioxane $(1.5 \mathrm{~mL})$ was moved through the $7 \% \mathrm{Pd} / \mathrm{WA} 30$-packed cartridge $(\varnothing 4.6 \times 50 \mathrm{~mm}$, SUS-316) by a syringe pump (YMC, YSP-101) at a 
flow rate of $0.05 \mathrm{~mL} / \mathrm{min}$. After transferring the entire reaction solution, the catalyst cartridge was washed with an additional mixed solvent of $\mathrm{H}_{2} \mathrm{O}(5 \mathrm{~mL})$ and 1,4-dioxane $(15 \mathrm{~mL})$. The combined reaction mixture and washing solution were extracted with ethyl acetate $(40 \mathrm{~mL} \times 2)$. The combined organic layers were dried over $\mathrm{Na}_{2} \mathrm{SO}_{4}$ and concentrated in vacuo. The residue was purified by silica gel column chromatography (hexane/ethyl acetate) to produce the corresponding coupling product 4 (Tables 1 and 2 and Figure 2).

\subsubsection{Procedure for the Continuous-Flow Suzuki-Miyaura Coupling of Aryl Chlorides with Aryl} Boronic Acids

A solution of aryl chloride (5, $0.25 \mathrm{mmol})$, aryl boronic acid $(3,0.50 \mathrm{mmol})$, and tetrabutylammonium fluoride $(0.50 \mathrm{mmol} ; 1 \mathrm{~mol} / \mathrm{L}$ in THF solution) was moved through the $7 \%$ Pd/WA30-packed cartridge ( $\varnothing 4.6 \times 50 \mathrm{~mm}$, SUS-316) by a syringe pump (YMC, YSP-101) at a flow rate of $0.05 \mathrm{~mL} / \mathrm{min}$. After transferring the entire reaction solution, the catalyst cartridge was washed with additional THF $(5 \mathrm{~mL})$ and then ethyl acetate $(15 \mathrm{~mL})$. The combined reaction mixture and washing solution were concentrated in vacuo. The residue was purified by silica gel column chromatography (hexane/ethyl acetate) to provide the corresponding coupling product 4 (Table 3, entry 6 and Figure 3).

\subsubsection{Procedure for the Continuous-Flow Suzuki-Miyaura Coupling Reaction over an Extended Time}

A solution of 4'-iodoacetophenone (1a, $2.5 \mathrm{~g}, 10.0 \mathrm{mmol})$, phenylboronic acid (3a, $1.5 \mathrm{~g}, 12.0 \mathrm{mmol})$, and $\mathrm{KOH}(1.1 \mathrm{~g}, 20 \mathrm{mmol})$ in a mixed solvent of $\mathrm{H}_{2} \mathrm{O}(10 \mathrm{~mL})$ and 1,4-dioxane $(30 \mathrm{~mL})$ was moved through a cartridge packed with $200 \mathrm{mg}$ of $7 \% \mathrm{Pd} / \mathrm{WA} 30(\varnothing 4.6 \times 150 \mathrm{~mm}$, SUS-316) by a syringe pump (YMC, YSP-101) at a flow rate of $0.05 \mathrm{~mL} / \mathrm{min}$ at $25^{\circ} \mathrm{C}$. The reaction solution was collected every $1 \mathrm{~h}$, changing the receiving vessel (1st; $0-1 \mathrm{~h}, 2$ nd; $1-2 \mathrm{~h}, 3 \mathrm{rd}$; $2-3 \mathrm{~h}, 4$ th; $3-4 \mathrm{~h}, 5$ th; $4-5 \mathrm{~h}, 6$ th; $5-6 \mathrm{~h}$, 7th; 6-7 h, 8th; 7-8 h, 9th; 8-9 h, 10th; 9-10 h, 11th; 10-11 h, 12th; 11-12 h, 13th; 12-13 h, 14th; 13-14 h). Each reaction solution was extracted separately with ethyl acetate $(10 \mathrm{~mL} \times 2)$, dried over $\mathrm{Na}_{2} \mathrm{SO}_{4}$, and concentrated in vacuo. Subsequently, each residue was analyzed by ${ }^{1} \mathrm{H}$ NMR. The combined residues were purified by silica-gel column chromatography (hexane/ethyl acetate $=15 / 1$ ) to obtain 4-acethylbiphenyl (4aa, $2.0 \mathrm{~g}, 10 \mathrm{mmol}$ ) in quantitative yield (Scheme 1).

\section{Conclusions}

The continuous-flow Suzuki-Miyaura coupling reaction of (hetero)aromatic iodides, bromides, and chlorides with (hetero)aryl boronic acids was developed using 7\% Pd/WA30-packed catalyst cartridges, where Pd was immobilized on the spherical chelate resin WA30. The present continuous-flow Suzuki-Miyaura reaction proceeded under ligand- and backpressure-free conditions. Coupling of aromatic iodides and bromides with aryl boronic acids was efficiently conducted by transferring a single reaction solution of aryl halides, aryl boronic acids, and inorganic bases dissolved in $\mathrm{H}_{2} \mathrm{O} / 1$,4-dioxane into a 7\% Pd/WA30-packed catalyst cartridge using a syringe pump. Using aryl chlorides as substrates, the addition of TBAF in THF instead of the inorganic base significantly improved the reaction efficiency. The ligand- and backpressure-free continuous-flow Suzuki-Miyaura reaction was also applied to the coupling of heteroaryl halides with heteroaryl boronic acids. The combination of base and solvent is quite crucial for preparing a homogeneously dissolved reaction solution consisting of an aromatic halide, aryl boronic acid, and organic or inorganic base. Furthermore, the provided void space in the cartridge derived from the spherical structures of the 7\% Pd/WA30 catalyst enables a smooth flow of the reaction solution using a single syringe pump. Clogging or serious backpressure was not observed. Therefore, the present ligand- and backpressure-free continuous-flow Suzuki-Miyaura coupling reaction is a facile and straightforward continuous-flow method for practical use in a variety of chemistry fields. 
Supplementary Materials: The following is available online at http://www.mdpi.com/2073-4344/10/10/1209/s1, Content 1: General; Content 2: Preparation of 7\% Pd/WA30; Content 3: Preparation of catalyst cartridge; Content 4: Experimental procedures; Content 5: Preliminary experiments for the solubility of the reaction solutions; Content 6: Optimization of the continuous-flow Suzuki-Miyaura coupling of 3'-iodoacetophenone and 2 '-iodoacetophenone; Content 7: Optimization of a reaction solvent for the continuous-flow Suzuki-Miyaura coupling of 3'-chloroacetophenone under batch conditions; Content 8: Spectroscopic data of products; Content 9: Procedure for the continuous-flow Suzuki-Miyaura coupling reaction over an extended period of time; Content 10: Leaching test for the continuous-flow Suzuki-Miyaura coupling of $4^{\prime}$-iodoacetophenone and $4^{\prime}$-chloroacetophenone; Content 11: References; Content $12:{ }^{1} \mathrm{H}$ and ${ }^{13} \mathrm{C}$ spectra of products.

Author Contributions: Writing—original draft and Supplementary Materials preparation, T.Y., N.I. and K.P.; designing the research, T.Y., K.P., N.I. and H.S.; investigation, experimental, and analysis, J.J., H.M., N.I., K.P., C.F., M.I. and S.Ō.; project administration, supervision, writing-review and editing, H.S. All authors have read and agreed to the published version of the manuscript.

Funding: This work is partially based on results obtained from a project commissioned by the New Energy and Industrial Technology Development Organization (NEDO, Project code: P19004).

Acknowledgments: We sincerely appreciate the N.E. Chemcat Co. for the kind gift of the 5\% Pd/CB and the Mitsubishi Chemical Co. for the kind gift of the HP20 and WA30.

Conflicts of Interest: The authors declare no conflict of interest.

\section{References}

1. Miyaura, N.; Suzuki, A. Palladium-Catalyzed Cross-Coupling Reactions of Organoboron Compounds. Chem. Rev. 1995, 95, 2457-2483. [CrossRef]

2. Hassan, J.; Sèvignon, M.; Gozzi, C.; Schulz, E.; Lemaire, M. Aryl-Aryl Bond Formation One Century after the Discovery of the Ullmann Reaction. Chem. Rev. 2002, 102, 1359-1470. [CrossRef]

3. Biffis, A.; Centomo, P.; Del Zotto, A.; Zecca, M. Pd Metal Catalysts for Cross-Couplings and Related Reactions in the 21st Century: A Critical Review. Chem. Rev. 2018, 118, 2249-2295. [CrossRef]

4. Bringmann, G.; Gulder, T.; Gulder, T.A.M.; Breuning, M. Atroposelective Total Synthesis of Axially Chiral Biaryl Natural Products. Chem. Rev. 2011, 111, 563-639. [CrossRef]

5. Wu, J.-S.; Cheng, S.-W.; Cheng, Y.-J.; Hsu, C.-S. Donor-acceptor conjugated polymers based on multifused ladder-type arenes for organic solar cells. Chem. Soc. Rev. 2015, 44, 1113-1154. [CrossRef]

6. Yin, L.; Liebscher, J. Carbon-Carbon Coupling Reactions Catalyzed by Heterogeneous Palladium Catalysts. Chem. Rev. 2007, 107, 133-173. [CrossRef]

7. Fihri, A.; Bouhrara, M.; Nekoueishahraki, B.; Basset, J.-M.; Polshettiwar, V. Nanocatalysts for Suzuki cross-coupling reactions. Chem. Soc. Rev. 2011, 40, 5181-5203. [CrossRef]

8. A Smith, D.; Krishnananthan, S.; Meanwell, N.A.; Mathur, A.; Li, J. Multigram Synthesis of BMS-929075, an Allosteric, Palm Site Inhibitor of HCV NS5B Replicase, Involving the Synthesis of a Highly Functionalized Benzofuran through a Telescoped Process. Org. Process Res. Dev. 2020, 24, 1157-1163. [CrossRef]

9. Konda, V.; Rydfjord, J.; Sämarker, J.; Larhed, M. Safe Palladium-Catalyzed Cross-Couplings with Microwave Heating. Using Continuous-Flow Silicon Carbide Reactors. Org. Process Res. Dev. 2014, 18, 1413-1418. [CrossRef]

10. Filipponi, P.; Ostacolo, C.; Novellino, E.; Pellicciari, R.; Gioiello, A. Continuous Flow Synthesis of Thieno[2,3-c]isoquinolin-5(4H)-one Scaffold: A Valuable Source of PARP-1 Inhibitors. Org. Process Res. Dev. 2014, 18, 1345-1353. [CrossRef]

11. Cole, K.P.; Reizman, B.J.; Hess, M.; Groh, J.M.; Laurila, M.E.; Cope, R.F.; Campbell, B.M.; Forst, M.B.; Burt, J.L.; Maloney, T.D.; et al. Small-Volume Continuous Manufacturing of Merestinib. Part 1. Process Development and Demonstration. Org. Process Res. Dev. 2019, 23, 858-869. [CrossRef]

12. Cole, K.P.; Campbell, B.M.; Forst, M.B.; Groh, J.M.; Hess, M.; Johnson, M.D.; Miller, R.D.; Mitchell, D.; Polster, C.S.; Reizman, B.J.; et al. An Automated Intermittent Flow Approach to Continuous Suzuki Coupling. Org. Process Res. Dev. 2016, 20, 820-830. [CrossRef]

13. Flick, A.C.; Ding, H.X.; Leverett, C.A.; Fink, S.J.; O’Donnell, C.J. Synthetic Approaches to New Drugs Approved During 2016. J. Med. Chem. 2018, 61, 7004-7031. [CrossRef] [PubMed]

14. Kuroda, K.; Tsuyumine, S.; Kodama, T. Direct Synthesis of a PDE4 Inhibitor by Using Pd-Cu-Catalyzed C-H/C-Br Coupling of Benzoxazole with a Heteroaryl Bromide. Org. Process Res. Dev. 2016, 20, 1053-1058. [CrossRef] 
15. Young, I.S.; Simmons, E.M.; Fenster, M.D.B.; Zhu, J.J.; Katipally, K.R. Palladium-Catalyzed C-O Coupling of a Sterically Hindered Secondary Alcohol with an Aryl Bromide and Significant Purity Upgrade in the API Step. Org. Process Res. Dev. 2018, 22, 585-594. [CrossRef]

16. Nicolaou, K.C.; Bulger, P.G.; Sarlah, D. Palladium-Catalyzed Cross-Coupling Reactions in Total Synthesis. Angew. Chem. Int. Ed. 2005, 44, 4442-4489. [CrossRef] [PubMed]

17. Bai, Y.; Davis, D.C.; Dai, M. Natural Product Synthesis via Palladium-Catalyzed Carbonylation. J. Org. Chem. 2017, 82, 2319-2328. [CrossRef]

18. Yamada, T.; Matsuo, T.; Ogawa, Y.; Ichikawa, T.; Kobayashi, Y.; Masuda, H.; Miyamoto, R.; Bai, H.; Meguro, K.; Sawama, Y.; et al. Application of Thiol-Modified Dual-Pore Silica Beads as Practical Scavenger of Leached Palladium Catalyst in C-C Coupling Reaction. Org. Process Res. Dev. 2019, 23, 462-469. [CrossRef]

19. Yamada, T.; Masuda, H.; Park, K.; Tachikawa, T.; Ito, N.; Ichikawa, T.; Yoshimura, M.; Takagi, Y.; Sawama, Y.; Ohya, Y.; et al. Development of Titanium Dioxide-Supported Pd Catalysts for Ligand-Free Suzuki-Miyaura Coupling of Aryl Chlorides. Catalysts 2019, 9, 461. [CrossRef]

20. Monguchi, Y.; Sakai, K.; Endo, K.; Fujita, Y.; Niimura, M.; Yoshimura, M.; Mizusaki, T.; Sawama, Y.; Sajiki, H. Carbon-Carbon Bond Formation by Ligand-free Cross-Coupling Reaction Using Palladium Catalyst Supported on Synthetic Adsorbent. Chem CatChem 2012, 4, 546-558. [CrossRef]

21. Monguchi, Y.; Wakayama, F.; Ueda, S.; Ito, R.; Takada, H.; Inoue, H.; Nakamura, A.; Sawama, Y.; Sajiki, H. Amphipathic monolith-supported palladium catalysts for chemoselective hydrogenation and cross-coupling reactions. RSC Adv. 2017, 7, 1833-1840. [CrossRef]

22. Maegawa, T.; Kitamura, Y.; Sako, S.; Udzu, T.; Sakurai, A.; Tanaka, A.; Kobayashi, Y.; Endo, K.; Bora, U.; Kurita, T.; et al. Heterogeneous Pd/C-Catalyzed Ligand-Free, Room-Temperature Suzuki-Miyaura Coupling Reactions in Aqueous Media. Chem. Eur. J. 2007, 13, 5937-5943. [CrossRef]

23. Monguchi, Y.; Ichikawa, T.; Yamada, T.; Sawama, Y.; Sajiki, H. Continuous-flow Suzuki-Miyaura and Mizoroki-Heck Reactions under Microwave Heating Conditions. Chem. Rec. 2019, 19, 3-14. [CrossRef]

24. Kobayashi, S. Flow "Fine" Synthesis: High Yielding and Selective Organic Synthesis by Flow Methods. Chem. Asian J. 2016, 11, 425-436. [CrossRef]

25. Masuda, K.; Ichitsuka, T.; Koumura, N.; Sato, K.; Kobayashi, S. Flow fine synthesis with heterogeneous catalysts. Tetrahedron 2018, 74, 1705-1730. [CrossRef]

26. Cantillo, D.; Kappe, C.O. Immobilized Transition Metals as Catalysts for Cross-Couplings in Continuous Flow-A Critical Assessment of the Reaction Mechanism and Metal Leaching. ChemCatChem 2014, 6, 3286-3305. [CrossRef]

27. Munirathinam, R.; Huskens, J.; Verboom, W. Supported Catalysis in Continuous-Flow Microreactors. Adv. Synth. Catal. 2015, 357, 1093-1123. [CrossRef]

28. Len, S.; Bruniaux, S.; Delbecq, F.; Parmar, V.S. Palladium-Catalyzed Suzuki-Miyaura Cross-Coupling in Continuous Flow. Catalysts 2017, 7, 146. [CrossRef]

29. Ichitsuka, T.; Suzuki, N.; Sairenji, M.; Koumura, N.; Onozawa, S.; Sato, K.; Kobayashi, S. Readily Available Immobilized Pd Catalysts for Suzuki-Miyaura Coupling under Continuous-flow Conditions. ChemCatChem 2019, 11, 2427-2431. [CrossRef]

30. De Muñouz, J.M.; Alcázar, J.; de la Hoz, A.; Díaz-Ortiz, A. Cross-Coupling in Flow Using Supported Catalysts: Mild, Clean, Efficient and Sustainable Suzuki-Miyaura Coupling in a Single Pass. Adv. Synth. Catal. 2012, 354, 3456-3460. [CrossRef]

31. Martin, A.D.; Siamaki, A.R.; Belecki, K.; Gupton, B.F. A Flow-Based Synthesis of Telmisartan. J. Flow Chem. 2015, 5, 145-147. [CrossRef]

32. Greenway, G.M.; Haswell, S.J.; Morgan, D.O.; Skelton, V.; Styring, P. The use of a novel microreactor for high throughput continuous flow organic synthesis. Sens. Actuators B Chem. 2000, 63, 153-158. [CrossRef]

33. Pandarus, V.; Gingras, G.; Béland, F.; Ciriminna, R.; Pagliaro, M. Process Intensification of the Suzuki-Miyaura Reaction over Sol-Gel Entrapped Catalyst SiliaCat DPP-Pd Under Conditions of Continuous Flow. Org. Process Res. Dev. 2014, 18, 1550-1555. [CrossRef]

34. He, P.; Haswell, S.J.; Fletcher, P.D.I. Microwave-assisted Suzuki reactions in a continuous flow capillary reactor. Appl. Catal. A Gen. 2004, 274, 111-114. [CrossRef]

35. He, P.; Haswell, S.J.; Fletcher, P.D.I.; Kelly, S.M.; Mansfield, A. Scaling up of continuous-flow, microwave-assisted, organic reactions by varying the size of Pd-functionalized catalytic monoliths. Beilstein J. Org. Chem. 2011, 7, 1150-1157. [CrossRef] 
36. Mennecke, K.; Kirschning, A. Polyionic Polymers-Heterogeneous Media for Metal Nanoparticles as Catalyst in Suzuki-Miyaura and Heck-Mizoroki Reactions under Flow Conditions. Beilstein J. Org. Chem. 2009, 5. [CrossRef]

37. Pascanu, V.; Hansen, P.R.; Bermejo-Gomez, A.; Ayats, C.; Platero-Prats, A.E.; Johansson, M.J.; Pericas, M.A.; Martin-Matute, B. Highly functionalized biaryls via Suzuki-Miyaura cross coupling catalyzed by Pd@MOF under batch and continuous flow regimes. ChemSusChem 2015, 8, 123-130. [CrossRef]

38. Greco, R.; Goessler, W.; Cantillo, D.; Kappe, C.O. Benchmarking immobilized Di- and Triaryphosphine palladium catalysts for continuous-flow cross-coupling reactions: Efficiency, durability, and metal leaching studies. ACS Catal. 2015, 5, 1303-1312. [CrossRef]

39. Mateos, C.; Rincón, J.A.; Martín-Hidalgo, B.; Villanueva, J. Green and scalable procedure for extremely fast ligandless Suzuki-Miyaura cross-coupling reactions in aqueous IPA using solid-supported Pd in continuous flow. Tetrahedron Lett. 2014, 55, 3701-3705. [CrossRef]

40. Brinkley, K.W.; Burkholder, M.; Siamaki, A.R.; Belecki, K.; Gupton, B.F. The continuous synthesis and application of graphene supported palladium nanoparticles: A highly effective catalyst for Suzuki-Miyaura cross-coupling reactions. Green Process Synth. 2015, 4, 241-246. [CrossRef]

41. Trinh, T.N.; Hizartzidis, L.; Lin, A.J.S.; Harman, D.G.; McCluskey, A.; Gordon, C.P. An efficient continuous flow approach to furnish furan-based biaryls. Org. Biomol. Chem. 2014, 12, 9562-9571. [CrossRef]

42. Hattori, T.; Tsubone, A.; Sawama, Y.; Monguchi, Y.; Sajiki, H. Palladium on carbon-catalyzed Suzuki-Miyaura coupling reaction using an efficient and continuous flow system. Catalysts 2015, 5, 18-25. [CrossRef]

43. Synthetic Adsorbent Based on a Polystyrene/Divinylbenzene Copolymer HP20 Is Commercially Available. Available online: https://www.diaion.com/en/products/synthetic_adsorbents/ (accessed on 10 September 2020).

44. Amphipathic and Monolithic Polystyrene/Divinylbenzene Copolymer Bearing Sulfonic Acid Moieties $\mathrm{CM}$ and Bearing Quaternary Ammonium Moieties AM Are Commercially Available. Available online: https://www.organo.co.jp/english/ (accessed on 10 September 2020).

45. Tertiary Amine-Functionalized Weakly Basic Anion Exchange Resin WA30 Is Commercially. Available online: https://www.diaion.com/en/products/ion_exchange_resins/weakly_basic_anion/index.html (accessed on 10 September 2020).

46. Yamada, T.; Kuwata, M.; Takakura, R.; Monguchi, Y.; Sajiki, H.; Sawama, Y. Organocatalytic Nitroaldol Reaction Associated with Deuterium-Labeling. Adv. Synth. Catal. 2018, 360, 637-641. [CrossRef]

47. Yamada, T.; Park, K.; Ito, N.; Masuda, H.; Teranishi, W.; Cui, S.; Sajiki, H. Robust Continuous-Flow Synthesis of Deuterium-Labeled $\beta$-Nitroalcohols Catalyzed by Basic Anion Exchange Resin. Bull. Chem. Soc. Jpn. 2020, 93, 1000-1006. [CrossRef]

48. Monguchi, Y.; Ichikawa, T.; Netsu, M.; Hattori, T.; Mizusaki, T.; Sawama, Y.; Sajiki, H. Tertiary-Amino-Functionalized Resin-Supported Palladium Catalyst for the Heterogeneous Suzuki-Miyaura Reaction of Aryl Chlorides. Synlett 2015, 26, 2014-2018. [CrossRef]

49. Ichikawa, T.; Netsu, M.; Mizuno, M.; Mizusaki, T.; Takagi, Y.; Sawama, Y.; Monguchi, Y.; Sajiki, H. Development of a unique heterogeneous palladium catalyst for Suzuki-Miyaura reaction using (hetero)aryl chlorides and chemoselective hydrogenation. Adv. Synth. Catal. 2017, 359, 2269-2279. [CrossRef]

50. Ichikawa, T.; Mizuno, M.; Ueda, S.; Ohneda, N.; Odajima, H.; Sawama, Y.; Monguchi, Y.; Sajiki, H. A practical method for heterogeneously-catalyzed Mizoroki-Heck reaction: Flow system with adjustment of microwave resonance as an energy source. Tetrahedron 2018, 74, 1810-1816. [CrossRef]

51. Wu, X.-M.; Gu, Y.-B. TBAF-Assisted Palladium-Catalyzed Suzuki Reaction in Water Under the Ligand and Base-Free Conditions. Lett. Org. Chem. 2012, 9, 396-400. [CrossRef]

52. Miyashita, K.; Sakai, T.; Imanishi, T. Total Synthesis of ( \pm )-Spiroxin C. Org. Lett. 2003, 5, 2683-2686. [CrossRef] [PubMed] 
53. Negishi, E.; Tobrman, T.; Rao, H.; Xu, S.; Lee, C.-T. Highly ( $\geq 98 \%$ ) Selective Trisubstituted Alkene Synthesis of Wide Applicability via Fluoride-Promoted Pd-Catalyzed Cross-Coupling of Alkenylboranes. Isr. J. Chem. 2010, 50, 696-701. [CrossRef]

54. Schmidt, B.; Riemer, M.; Karras, M. 2,2-Biphenols via Protecting Group-Free Thermal or Microwave-Accelerated Suzuki-Miyaura Coupling in Water. J. Org. Chem. 2013, 78, 8680-8688. [CrossRef] [PubMed]

Publisher's Note: MDPI stays neutral with regard to jurisdictional claims in published maps and institutional affiliations.

(C) 2020 by the authors. Licensee MDPI, Basel, Switzerland. This article is an open access article distributed under the terms and conditions of the Creative Commons Attribution (CC BY) license (http://creativecommons.org/licenses/by/4.0/). 